\title{
MARIJUANA
}

\section{The user}

Marijuana has been referred to as "the great leveller" since it is used by all classes; that is, the very poor, the middle class and the very rich. It is used by people of all ages.

The general impressions gained from interviews and questionnaires so far are that many of the younger Marijuana smokers are young adults who say they are in search of an identity which the allowed modes of expression in a conformist, materialistic society seem to deny them. Others come from the kinds of background which endanger personality development such as broken homes, unfit parents, and lack of parental concern. Others simply are looking for kicks. To be sure, their attitudes toward work, love, sex, and play are somewhat different from those of society. That some of these young people seek to substitute a drug-using clique for healthy family interaction seems one of the more deplorable aspects of this rebellion via Marijuana.

A recent survey by the New York Times found that, while still a small minority of the population, more and more on-the-way-up and already successful adults are using Marijuana and other hallucinogenic drugs. According to Dr. William McGlothin, a psychologist at the University of California, the adult usually experiments with drugs like Marijuana cautiously and in a way that will not abruptly change his daily living pattern. Many of the adults interviewed in this survey say they use Marijuana to escape boredom or what they believe to be their remoteness from meaningful activity. Some, but not all, say they are searching for sexual freedom. Others say they seek a passageway to their own subconscious.

\section{Possible consequences of prolonged use}

The literature clearly supports that Marijuana is not addiction producing with the twin signs of tolerance and physical dependence so characteristic of opiate addiction. There is no confirmed evidence as yet whether or not it produces psychological dependence, or whether it is simply a pleas- ant habit, hard to be broken once well established. Despite the claims of Marijuana smokers that they can voluntarily discontinue use at any time without experiencing undue suffering or craving, confirmed users bitterly resent deprivation and readily admit their future intentions to return to the drug as soon as conditions permit. No physical withdrawal symptoms seem to occur when the user stops the use of Marijuana abruptly.

The social consequences of prolonged Marijuana use seem to be far more detrimental to the individual and to society than any of the physical consequences.

Since the sale and possession of Marijuana is illegal, it must be secured by illegal means, necessitating secrecy, cunning and knowledge of distribution channels. Thus by association, Marijuana smokers might be drawn into a group of law-breakers, and may soon adopt at least some of the practices to which this group subscribes.

Young people who smoke Marijuana frequently and engage in its distribution, drop out of normal socially approved activities. By concentrating their activities in a small group of like persons, they limit their chances to grow and mature through the varied stimuli the world around offers.

Heavy Marijuana users or "pot-heads" who are more or less constantly high soon drop out of the productive process as well. They constantly defend their individual freedom yet expect to be maintained by those who subject their individual freedom to the good of society.

Fortunately the "pot-head" accounts for only a small number of the persons who smoke Marijuana. The majority of Marijuana smokers fall as yet into a rather "grey" category about which little can be said. They generally adhere to socially approved modes of conduct and also work at socially approved jobs.

However, there is also a small group of Marijuana smokers whose unstable personal make-up will lead them to experiment with other drugs, especially those of the opiate variety. These young people are then in great danger of becoming hooked. 